\author{
Cadernos de \\ ESTUDOS LINGUUISTICOS - (59.2), Campinas, pp. 419-437 - mai./ago. 2017
}

\title{
ÍCONES METAFORIZADOS E ICONICIDADE EM LIBRAS
}

\author{
CRISTIAN SANTOS* \\ (UFC)
}

\begin{abstract}
RESUMO: Neste trabalho, parte adaptada de minha dissertação de mestrado, eu reflito sobre o que exatamente implica na iconicidade de algumas unidades linguísticas da Libras, principalmente naquelas que estão relacionadas a domínios abstratos: emoções e sentimentos, por exemplo. Alicerçado nos pressupostos da Linguística Cognitiva, eu defendo a ideia de que há um processo de conceitualização proporcionando o surgimento de um tipo de sinal que reúne em sua base razão, imaginação, metáfora, iconicidade e evidências de experiências corporificadas da comunidade surda.
\end{abstract}

Palavras-chave: Libras. Iconicidade. Experiências culturais

\begin{abstract}
In this paper, an adapted part of my masters dissertation, I reflect on what exactly implies in the iconicity of some linguistic units of Brazilian Sign Language (LSB), mainly the signs that are linked to abstract domains: emotions and feelings, for instance. Based on Cognitive Linguistics, I support the idea that there is a type of sign that gather in its base reason, imagination, metaphor, iconicity, and embodiment experiences evidences of deaf community.
\end{abstract}

Key-words: LSB. Iconicity. Cultural experiences

\section{INTRODUÇÃO}

Quem acompanhou o surgimento do Gerativismo de Noam Chomsky pôde assistir à consequente morte agoniante do Behaviorismo de Burrhus Skinner. Particularmente, não pretendo discutir as idealizações chomskyanas de falante ideal, de língua autônoma e dissociada do meio, uma vez que não há como fechar os olhos para o fato de que a relação do corpo do sujeito com o mundo à sua volta implica diretamente na construção e estruturação da gramática; muito menos pretendo fazer uma exumação no Behaviorismo, dado que os processos cognitivos são revelados pela linguagem e, portanto, são passíveis de estudos. No entanto, não posso deixar de pontuar que os primeiros passos em Linguística Cognitiva surgiram pelo desconforto diante das reflexões postuladas por Skinner (1957) e, também, pelo descontentamento de diversos linguistas ${ }^{1}$ em face dos

*em.cristian@gmail.com

${ }^{1}$ Cf. Charles Fillmore (1976), George Lakoff (1987), George Lakoff e Mark Johnson (2003), Leonard Talmy (1983), Mark Johnson (1987), Ronald Langacker (1987) entre outros. 
resultados insatisfatórios (pelo menos para os dissidentes) da Gramática Gerativa de Noam Chomsky, ainda nos anos 1970. O primeiro (Skinner) excluiu a mente de seus estudos, porque somente os comportamentos humanos seriam passíveis de observação; o segundo (Chomsky) encaminhou o significado para a periferia dos estudos da linguagem e acomodou a sintaxe como objeto principal de análise, mas sem levar em consideração as experiências externas do sujeito. Agora, no novo paradigma, cognição, corpo, cultura e relação do ser humano com o mundo possuem uma íntima relação, por isso compõem a agenda de investigações dos linguistas cognitivos.

Em consequência de sua vasta abrangência, a Linguística Cognitiva proporcionou um arcabouço teórico muito extenso, onde os estudos em línguas de sinais também encontram condições especialmente favoráveis para reflexões de fenômenos antes enigmáticos, vagos, ininteligíveis ou mesmo inexplorados pelas pesquisas. Neste trabalho, que é apenas um recorte adaptado de minha dissertação de mestrado, eu apresento e explico alguns fenômenos da Língua Brasileira de Sinais (Libras), um deles está relacionado com a iconicidade, onde a comunidade surda brasileira, baseada em suas experiências corpóreo-culturais, fez surgir o que chamo de sinais icônicos metaforizados. Mas antes de apresentá-los, é necessário trazer alguns conceitos importantes, explicados nas seções seguintes.

\section{CONCEITOS E CONCEITUALIZAÇÕES}

Um piscar de olho ou um olhar contumaz para alguém, uma pintura, um desenho, um sinal, uma mímica, uma palavra, um texto, enfim, tudo o que comunica possui forma e significado. Para a Semântica Cognitiva, o significado está vinculado à representação mental e é o resultado de nossas conceitualizações, construídas a partir de nossa exposição ao mundo e de nossas interações com ele. Como resultado de nossas conceitualizações, uma mesma unidade simbólica (palavra ou sinal) em dois ou mais contextos de uso pode indicar significados distintos. Isso sugere que o significado não é uma única "coisa" a ser empacotada pela língua (Evans, 2007, p. 131 e 132), antes é uma negociação entre os interlocutores em dado contexto. Por esse viés, parece ser mais razoável conceber as unidades linguísticas como instruções para os interlocutores realizarem conceitualizações e produzirem significados, produzidos no nível conceitual. Esse fato é importante porque sendo a conceitualização o processo de construção do significado, este deixa de ter uma relação direta com o mundo e passa a ser mediado pela cognição. Por exemplo, os sinais CARINHO e ÓDIO, em Libras, evidenciam uma relação indireta com fatores externos: o primeiro possui relação com eventos que sugerem "alguém acariciando outrem", o segundo sugere "recipientes pressurizados", e a mediação cognitiva entre o mundo externo e o significado pode ser percebida na projeção metafórica dos sinais, como mostrarei mais adiante. Por isso é possível dizer que os significados das línguas são equivalentes aos conceitos expressos por elas (Clausner e Croft, 1999, p. 2) e estão "na cabeça” dos interlocutores. 
Conceitualizar é gerar conceitos, unidades mentais estruturantes do conhecimento. Logo, a conceitualização é um fenômeno mental, mas baseada em nossas experiências corporais (percepção, toque, visão, sabores etc.), culturais (negociações entre os sujeitos de uma mesma cultura) e subjetivas. Obviamente, não existe máquina capaz de observar os conceitos, mas muito da linguagem humana revela seus aspectos e abstrações. Por exemplo, nossa prática inconsciente de usar metáforas no dia a dia mostra como nosso processamento cognitivo une razão à imaginação, além de demonstrar que muitos conceitos estão ligados a experiências corporais e culturais. Dito isso, é possível notar uma diferença crucial entre o significado defendido pela Semântica Cognitiva e o defendido pela Semântica Formal. Para esta, o significado é visto como uma relação entre realidade externa e linguagem, sendo esta o reflexo da realidade; para aquela, o significado é visto como a relação entre pensamento e linguagem, sendo esta o reflexo do pensamento.

\section{DOMÍNIOS}

Outro pressuposto da Linguística Cognitiva e importante para este trabalho é o de "domínio", entendido como uma estrutura de conhecimento. Ele surge de nossas experiências físicas (toque, abraço, carinho, dor etc.), de nossa propriocepção (equilíbrio, noção de localização espacial, movimento, orientação etc.), percepções (cores, sons, cheiro etc.), por nossas habilidades em manipular objetos e pelas experiências subjetivas que dão origem a domínios relacionados, principalmente, a emoções e a sentimentos, tais como MEDO, JUSTIÇA, HONRA, AMOR ${ }^{2}$. Ao passo em que nossas experiências pré-conceituais acontecem, ainda quando crianças, estruturas de conhecimento formam-se no sistema conceitual e proporcionam a base para o entendimento de conceitos lexicais. Esse esclarecimento é importante porque é o fundamento para compreendermos boa parte do funcionamento, do surgimento, da organização e do uso das projeções metafóricas.

Para a Linguística Cognitiva, nosso sistema conceitual é estruturado em termos de domínios mais concretos (domínio-fonte) e outros mais abstratos (domínio-alvo). Para entender ou estruturar um determinado domínio conceitual abstrato, nossa cognição pode recorrer a um determinado domínio conceitual concreto. Isso se reflete na linguagem em termos de metáforas linguísticas, mas subjacentes a elas encontramos as metáforas conceituais, em virtude do mapeamento entre os domínios realizado pela cognição. Por exemplo, ao analisarmos a metáfora linguística "não desista de viver, continue caminhando", percebemos dois domínios conceituais envolvidos nessa projeção: ESTRADA, domínio-fonte, e VIDA, domínio-alvo. A frase indica que o enunciador acessa o domínio-fonte ESTRADA (mais concreto) para estruturar o domínio-alvo VIDA (mais abstrato). Esse mapeamento cognitivo feito entre os dois domínios gera a metáfora conceitual VIDA É UMA ESTRADA.

\footnotetext{
${ }^{2}$ Para representar conceitos, a Linguística Cognitiva utiliza todas as letras maiúsculas.
} 
Os domínios devem ser entendidos de forma abrangente. Em ESTRADA, encontramos conceitos como INÍCIO, MEIO e FIM; ESTRADA CURTA e ESTRADA LONGA; PEDRAS, OBSTÁCULOS, TRANSEUNTES; VÁRIAS VEREDAS e assim sucessivamente. Em VIDA, temos conceitos como NASCIMENTO, ABRIR OS OLHOS, JUVENTUDE, FASE ADULTA, VELHICE, PROBLEMAS, DIFICULDADES, DOENÇAS, FAMILIARES, AMIGOS, AMORES etc. Como o domínio-fonte é a base para a compreensão do domínio-alvo, então todos os conceitos (ou boa parte deles) pertencentes a um servirão de alicerce para o entendimento do outro: ao nascer, abrimos nossos olhos pela primeira vez (entendido como início da estrada); chegamos à juventude e à fase adulta (entendido como meio da estrada); chegamos à velhice, e no momento da morte fechamos nossos olhos pela última vez (entendido como o fim da estrada); mas podemos morrer precocemente (estrada curta) ou muito velhinho (estrada longa); enfrentamos problemas, dificuldades, doenças, tristezas, decepções, frustrações (pedras e obstáculos na estrada); temos familiares, conhecemos amigos e amores, vemos pessoas estranhas (transeuntes); podemos ter religiosidade, ser pacificadores, usar drogas, entrar na criminalidade (as várias veredas), e assim por diante.

Geralmente, o mapeamento acontece quando precisamos compreender domínios conceituais mais abstratos. Contudo, mesmo um domínio concreto pode ser entendido por meio de outro concreto, ou um abstrato ser estruturado por outro abstrato. Evidências como essas, além de revelarem nossas experiências corporificadas, subjetivas e culturais, mostram como nossas interações com o mundo implicam diretamente na organização e formação de nosso sistema conceitual, incluindo-se aí a própria gramática.

\section{ESQUEMAS IMAGÉTICOS}

A partir de nossa exposição ao mundo, ainda quando crianças, antes mesmo da formação de nossos primeiros conceitos, temos acesso a diversos tipos de experiências sensoriais e motoras. Nossa posição deitado nos braços de nossa mãe dá-nos um panorama visual de baixo para cima. Há momentos, quando estamos em outras posições ainda nos braços de nossa mãe, nossa experiência visual fornece-nos um panorama de cima para baixo, uma cena repetida quando começamos a dar os primeiros passos, por causa da projeção vertical de nossos corpos. Não só realizamos movimentos pelo espaço, mas, ao fazê-los, percebemos objetos aproximando-se e distanciando-se, ficando para trás, à frente, de lado, à direita, à esquerda. Nosso contato com, e a percepção de, objetos em forma de recipiente - caixa, garrafa, copo, vaso, jarra, sacolas, quarto, a própria casa etc. - fornecem-nos informações do tipo "dentro-fora", "cheio-vazio" e "conteúdo". Todas essas experiências e tantas outras são constantemente repetidas durante a vida, mas são nos primeiros estágios, quando a linguagem ainda nem está desenvolvida, que, de forma natural, os padrões recorrentes dessas experiências fornecem estruturas esquemáticas básicas que ajudarão no surgimento de conceitos 
mais elaborados. Essas estruturas esquemáticas abstratas são conhecidas como esquemas imagéticos, ${ }^{3}$ pensadas primeiramente por Johnson (1987) e reforçados por outros pesquisadores (Lakoff, 1987; Lakoff e Turner, 1989; Evans e Green, 2006; Clausner e Croft, 1999 entre outros).

O esquema imagético não é inato (Evans e Green, 2006, p. 178), não é exclusivamente mental, nem unicamente corpóreo, mas possui uma natureza corpóreo-mental. Assim como outros fenômenos, ele também estrutura nosso sistema conceitual, apesar de não ser rico em detalhes. É nesse sentido que a expressão "esquema imagético" faz jus ao seu significado, i.e., não estamos diante de uma imagem detalhada, mas esquemática, e ela não equivale à imagem mental. Enquanto esta é discriminada, aquela é simplificada. Para ficar mais claro, e mostrar a diferença entre uma e outra, Johnson (1987, p. 24) cita o exemplo da face humana, onde podemos imaginá-la com muitas especificidades, pupilas dilatadas, lábios rachados pela exposição excessiva da pessoa em um dia ensolarado, cicatriz abaixo do olho e várias outras particularidades - imagem mental. Por outro lado, o esquema imagético é esquemático, com poucos detalhes, focando apenas traços da face, nariz, olhos, boca etc., sem singularidades. Por esse viés, os esquemas imagéticos "são estruturas que organizam nossas representações mentais em um nível mais geral e abstrato do que aquele nível no qual formamos imagens mentais particulares"4 (JOHNSON, 1987, pp. 23-24). Conforme os padrões das informações sensoriais ficam recorrentes, essas estruturas dão origem a conceitos mais elaborados, desempenhando importante papel na conceitualização. Clausner e Croft (1999, p. 4) classificam os esquemas como domínios esquemático-imagéticos, ${ }^{5}$ pois os concebem como um subtipo de domínio. Mesmo assim, os mesmos autores salientam o fato de domínio básico não ser o mesmo que esquema imagético.

A partir do que foi exposto, vale a pena trazer alguns exemplos de esquemas imagéticos, porém, enfrentamos um grande problema: como ilustrar elementos prélinguísticos, i.e., como descrever um padrão esquemático não linguístico contido em nosso sistema conceitual? Evans e Green (2006, p. 180) também confirmam essa dificuldade, e destacam que em alguns casos os semanticistas precisam usar palavras e, em outros, diagramas. Usando estes últimos, é possível representar um conceito independente da língua envolvida na análise, mas é importante destacar que, embora as imagens e as palavras sejam usadas na tentativa de descrever os esquemas, estes não estão em nossas mentes como essas formas simbólicas, mas como experiências sensoriais holísticas, ou resumos de estados perceptuais "gravados" na mente (Evans e Green, 2006, p. 184). As ilustrações abaixo mostram alguns exemplos.

${ }^{3}$ image schema (Johnson, 1987, p. xiv)

${ }^{4}$ A não ser que eu diga o contrário, todas as traducões de trechos em outra língua que não podem ser encontrados em Português neste atigo são de minha responsabilidade. Portanto, no original temos: [They] are structures that organize our mental representations at a level more general and abstract than that at witch we form particular mental images.

${ }^{5}$ Image eschematic domains. 

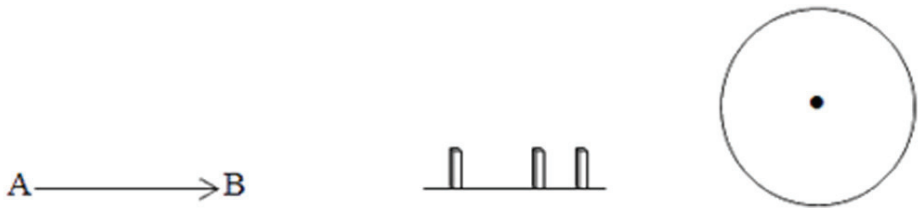

Ilustração 1 - Exemplos de esquemas imagéticos

Fonte: Elaborada pelo autor

Para explicar os dois primeiros, precisamos lembrar-nos de pelo menos duas experiências pré-conceituais: nossos movimentos pelo espaço e nossa percepção e manipulação de objetos espalhados ou organizados nele. Sobre a primeira experiência, Levinson (1996, p. 179) faz uma reflexão instigante ao pressupor que "a compreensão espacial é, provavelmente, a primeira grande atividade intelectual diante da criança". ${ }^{6}$ Essa experiência repetida muitas vezes em nossa vida fornece-nos o esquema imagético TRAJETÓRIA, representado pela ilustração 1.a. De forma semelhante, devido aos nossos corpos serem como são, principalmente por seu aspecto simétrico - lado direito e lado esquerdo, frente e atrás, interior e exterior, cima e baixo - agregado à nossa percepção e manipulação de objetos no espaço, possuímos vários esquemas imagéticos relacionados a essas experiências: FRENTE-ATRÁS, PRÓXIMO-DISTANTE, CIMA-BAIXO, LADO ESQUERDO-LADO DIREITO etc.

Nossas experiências diariamente repetidas com objetos em forma de recipiente também proporcionam outros esquemas corporificados. ${ }^{7}$ Esses objetos podem ser caixa, copo, jarros, quartos, salas, casas, sacolas entre outros. Johnson (1987, pp. 21 e 22) também acrescenta que, em virtude de seus formatos e suas finalidades, objetos semelhantes a esses possuem característica de abrigar entidades. Nossas interações com eles proporcionam ao nosso sistema conceitual o surgimento do esquema imagético CONTÊINER, representado pela figura 1.c. Em virtude de nossas experiências com esses objetos, nossa cognição projeta em nosso corpo um contentor capaz de guardar o que concebemos como concreto (sangue e órgãos vitais) e como imaterial (sentimentos e emoções). Provavelmente esse seja o motivo de realizarmos projeções conceituais tomando o esquema imagético CONTÊINER (mais concreto) para apoiar conceitos mais abstratos, tais como VIDA, RAIVA, AMOR etc., como vou mostrar a partir da próxima seção.

\footnotetext{
${ }^{6}[\ldots]$ spatial understanding is perhaps the first great intellectual task facing the child.

${ }^{7}$ Assim também são chamados os esquemas imagéticos
} 


\section{SINALIZA QUE OS ESQUEMAS IMAGÉTICOS APARECEM}

Agora, o desafio está em sustentar tais hipóteses, ou seja, como não podemos fazer uma foto dessas estruturas, de que forma elas se revelam? Por enquanto, a melhor maneira é buscar evidências na linguagem, afinal de contas, sendo a linguagem o reflexo da mente, ela pode revelar muito do sistema conceitual. Para trazer um exemplo, em Three Queens (Três Rainhas), um dos poemas de Paul Scott, poeta surdo britânico, TEMPO é organizado em três locais distintos, para referenciar três reinados de épocas diferentes: o de Elizabeth II, o de Victoria e o de Elizabeth I. Portanto, ele é compreendido em termos do domínio ESPAÇO, como mostra a figura 1 , a seguir.

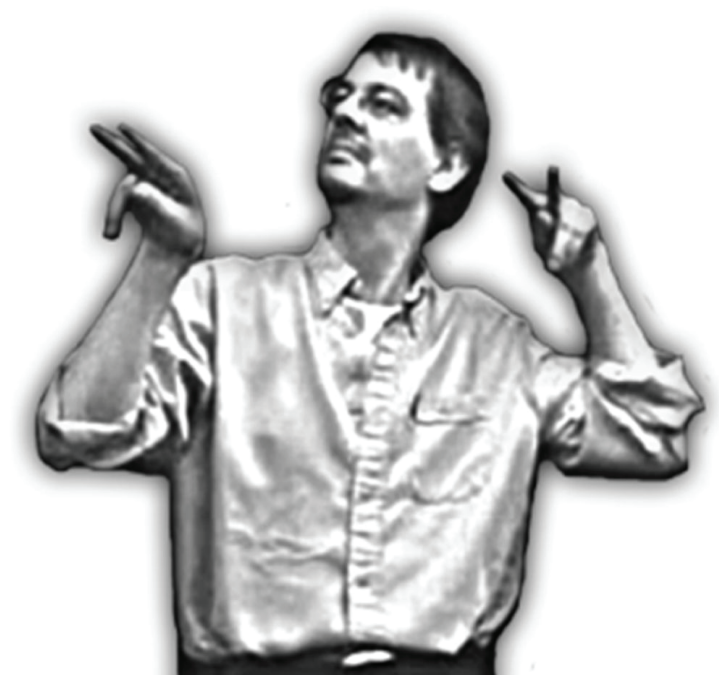

Figura 1 - Tempo sendo conceituado como espaço, em Língua de Sinais Britânica. Fonte: Adaptada de Sutton-Spence e Quadros (2006).

Na sinalização acima, o poeta usa as mãos e os olhos para fazer alusão ao olhar de três rainhas, contemplando a bandeira hasteada da Inglaterra. Mais do que isso, ele faz referência a três tempos diferentes. Portanto, nesse uso metafórico, TEMPO é conceitualizado em termos de ESPAÇO, no qual as três rainhas estão em três localizações espaciais distintas, devido terem vivido em épocas distintas. Sabendo da existência dessa metáfora, é possível analisar de que forma ela está organizada cognitivamente. Em primeiro lugar, ela se baseia no esquema imagético FRENTE-ATRÁS. Observe que o enunciador descortina esse esquema ao usar seu corpo como referência para localizar "três tempos diferentes". Observe também que a sinalização acima é um reflexo da ilustração 1.b. Em segundo lugar, como o domínio TEMPO é mais abstrato, o padrão esquemático FRENTE-ATRÁS juntamente com o domínio básico ESPAÇO organizam TEMPO à frente (futuro), no lugar do enunciador ou atrás do enunciador (passado). Assim, TEMPO é estruturado metaforicamente como localidades no espaço. 
Esse tipo de projeção conceitual é comum. Para nossa cultura, o tempo pode estar bem distante para frente (futuro), pode estar atrás (passado) ou no lugar em que nosso corpo está (presente). Em Libras, sinais como FUTURO, PASSADO, PRESENTE, ANTES, DEPOIS, ONTEM e HOJE também comprovam essas projeções conceituais. A propósito, tomando como referência o nosso corpo, o tempo também pode chegar e ir embora ("chegou a sua hora", "seu tempo já se foi"), além de ser associado a comprimento físico ("o tempo é curto", "o tempo é longo"); e a valor ("o tempo é valioso").

Como o domínio ESPAÇO e o esquema imagético FRENTE-ATRÁS estão sendo usados como base para a conceitualização de TEMPO, as projeções na figura 1 evidenciam pelo menos duas metáforas conceituais: TEMPO É ESPAÇO e TEMPO É ORGANIZAÇÃO DE OBJETOS (ou PESSOAS) NO ESPAÇO. Nessas situações, as conceitualizações estão estruturando o tempo atrás (passado), no lugar em que o sujeito está (presente - mas como projeção de alguém do passado) e na frente do sujeito (futuro), mostrando que os esquemas são representações analógicas de nossas experiências. Essas metáforas também fornecem evidências de que nossas conceitualizações produzem novos e diferentes significados para uma determinada unidade linguística. TEMPO pode ser entendido como COMPRIMENTO ou como VALOR, em alguns casos - "o tempo é longo" e "o tempo é valioso" - mas na figura 1, ele possui um conceito distinto destes dois últimos. A estruturação metafórica envolvida na sinalização da figura 1 é a seguinte:

$>$ Esquema imagético: FRENTE-ATRÁS.

$>$ Domínio conceitual abstrato: TEMPO.

$>$ Os conceitos PASSADO, PRESENTE e FUTURO pertencem ao domínio

$>$ TEMPO e também estão baseados no esquema imagético FRENTE-ATRÁS.

Metáforas conceituais mais gerais:

○ TEMPO É ESPAÇO.

- TEMPO É ORGANIZAÇÃO DE OBJETOS (ou PESSOAS) NO ESPAÇO.

Metáforas conceituais mais específicas, baseadas no esquema imagético FRENTE-ATRÁS:

- PASSADO ESTÁ ATRÁS DO CORPO DO ENUNCIADOR.

- PRESENTE É O LUGAR EM QUE O ENUNCIADOR ESTÁ.

- FUTURO ESTÁ À FRENTE DO CORPO DO ENUNCIADOR.

É importante destacar também que, na figura 1, constatamos a existência das metáforas conceituais quando analisamos o discurso e percebemos evidências dos mapeamentos entre os domínios fonte e alvo. Mas seria possível uma relação metafórica entre a estrutura fonológica, a estrutura semântica e o objeto 
representado? Ou seja, seria possível uma conceitualização a ponto de o polo fonológico ser usado metaforicamente para o entendimento do polo semântico em analogia ao referente ou à experiência externa? Tudo indica que em língua de sinais isso é possível e comum. Há conceitualizações fazendo uso metafórico da forma para se aproximar do significado a partir das conceitualizações do referente, proporcionando o surgimento de um tipo específico de iconicidade, e pelo fato de eu ainda não ter encontrado na literatura teorizações a esse respeito, eu passo a chamar o processo de "metaforização icônica", e a unidade simbólica criada pelo processo de "ícone metaforizado", como será detalhado a seguir.

\section{METAFORIZAÇÃO ICÔNICA EM LÍNGUAS DE SINAIS}

Um estudo sobre a iconicidade em Libras, usando como pano de fundo a Gramática Cognitiva de Langacker (1987), pode evidenciar em que medida os processos cognitivos realizam analogias baseadas em experiências cotidianas, e como as estruturas mais básicas do sistema conceitual são usadas para fundamentar a compreensão e o uso de sinais icônicos. Para iniciar a análise da iconicidade, sugiro partirmos da observação da unidade simbólica BOLA, em Libras, conceitualizada a partir de experiências com algo físico no mundo que lhe serve como referenciação literal, ou seja, ao olharmos para o sinal BOLA e para o objeto representado, vamos constatar uma referenciação não metafórica.

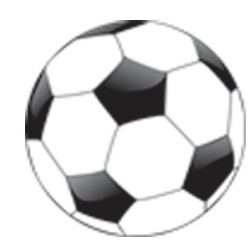

Figura 1 - bola de futebol

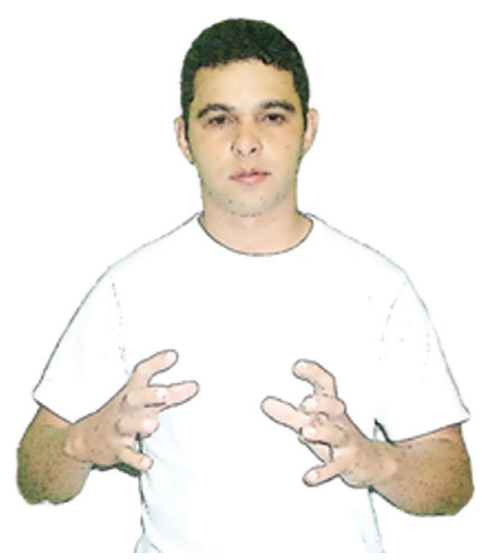

Figura 2 - Iconicidade do sinal BOLA

Fonte: Elaborada pelo autor

Essa unidade simbólica é constituída de uma estrutura semântica (vou representá-la pela notação [BOLA]) e de uma estrutura fonológica (vou representá-la pela notação [bola]). A primeira está fundamentada sobre várias características do objeto: tamanho, cor, forma, composição, função etc.; a segunda reúne os parâmetros 
configuração de mão, ponto de articulação, movimento, orientação da palma da mão e expressões faciais (se for o caso). A união do polo semântico com o polo fonológico constitui o sinal BOLA, e podemos representar a relação entre os polos por meio da notação [BOLA]/[bola], como é feito em Semântica Cognitiva (veja Langacker 1987, p. 89). Já que o espaço conceitual envolve todo o conhecimento, incluindo o pensamento, e enquanto os dois polos da estrutura simbólica BOLA possuem similaridades, então a arbitrariedade é reduzida e a iconicidade acentuada, originando uma relação de semelhança entre o polo fonológico, o polo semântico e o objeto no mundo. Em outras palavras, por meio da mediação cognitiva, polos fonológico e semântico e objeto no mundo são correlatos no sinal da Libras.

Cognitivamente, os polos também podem ser pensados em termos de espaço fonológico e espaço semântico. Enquanto este último é compreendido como um potencial conceitual no qual nossos pensamentos e nossas conceitualizações desdobram-se, o primeiro refere-se à nossa potencial capacidade de lidar com sons, especialmente os da fala (Langacker, 1987, p. 76), ou com os parâmetros dos sinais. Fundamentado nesse ponto de vista, a estrutura fonológica também é abrangida pelo espaço conceitual, assim como acontece com a semântica. A partir da organização entre os espaços, as estruturas simbólicas (sinais e palavras) podem ser caracterizadas como configurações que acontecem no espaço conceitual. Para o estudo da iconicidade em línguas de sinais, esses conceitos são importantes porque não apenas o polo semântico pode ser entendido como um resultado de conceitualizações, mas também o fonológico.

Wilcox (2004a) defende a ideia de que quando as similaridades entre as estruturas fonológica e semântica são acentuadas, ambas residem em um mesmo local do espaço conceitual, entendido como sendo multidimensional. Do contrário, i.e., se a dissimilaridade é assinalada, então as estruturas fonológica e semântica residem em locais distintos do espaço conceitual. Seria o caso do sinal PESSOA, em Libras, onde os polos da unidade linguística não possuem relações singulares entre si, nem mesmo com o referente concreto no mundo.

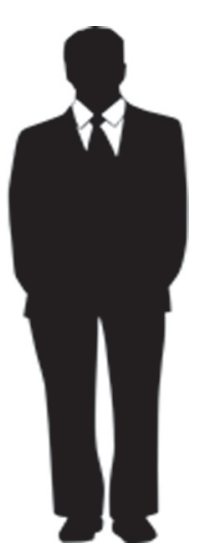

Figura 3.a - Shilueta de uma pessoa

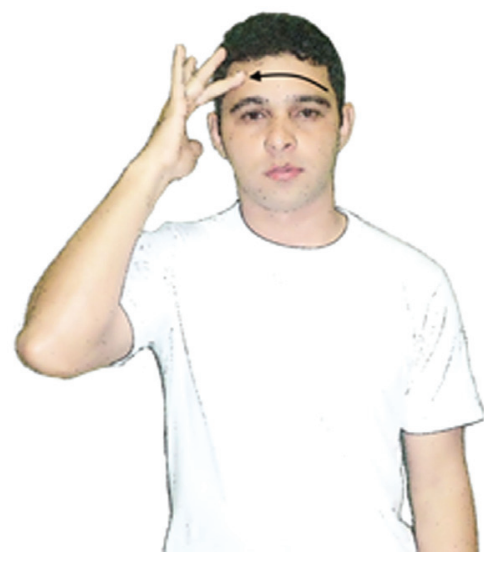

Figura 3.b - Sinal PESSOA, em Libras

Fonte: Elaborada pelo autor 
Fundamentado na Gramática Cognitiva de Langacker (1987), Wilcox (2004a) chama de iconicidade cognitiva (cognitive iconicity) a relação entre os polos. Usando suas palavras: "A iconicidade cognitiva é uma relação de distância entre os polos fonológico e semântico de estruturas simbólicas" (WILCOX, 2004a. p.122). O vínculo, portanto, não está entre a forma do sinal e o objeto, mas, antes, entre os espaços conceituais. Quando há um distanciamento entre forma e expressão, isso resulta no aumento da arbitrariedade e distanciamento dos espaços conceituais.

Com base no entendimento de que o polo fonológico de sinais da Libras pode revelar as conceitualizações da cultura surda, sugiro uma busca por mais indícios dessas manifestações. Minha intenção é dar conta de um grande número de sinais que possuem motivação icônica, mas por serem ligados a domínios abstratos não são concebidos como sinais icônicos pela visão tradicional de iconicidade. Afinal de contas, como uma unidade lexical relacionada a um domínio abstrato pode ter motivação icônica? Para chegar à resposta, vou priorizar sinais ligados a domínios abstratos (sentimentos e emoções, por exemplo). Bons representantes são os sinais ÓDIO e MALDADE, mas poderiam ser também AMOR, CARINHO, SAUDADE, RAIVA, DIFICULDADE, ESQUECIMENTO entre outros. Começando com ÓDIO, um olhar atento para a estrutura fonológica perceberemos que a configuração de mão (punho cerrado) indica um objeto esférico comprimido; o ponto de articulação (torso) sugere o contentor onde o objeto esférico está preso; o movimento ascendente, lento ou abrupto, reforça o conceito de alguma coisa prestes a explodir; a expressão facial revela um sentimento de aversão, incômodo, rejeição, raiva ou ódio propriamente dito. A junção desses articuladores resulta no seguinte sinal.

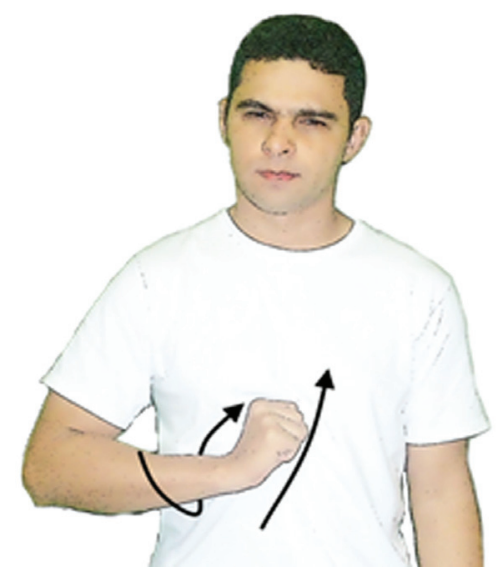

Figura 4 - Sinal ÓDIO

Fonte: Elaborada pelo autor

${ }^{8}$ Cognitive iconicity is a distance relation between the phonological and semantic poles of symbolic structures. 
Diante da relação [ÓDIO]/[ódio] com o tipo de experiência corpóreo-cultural da comunidade surda brasileira, quero destacar três aspectos cognitivos. O primeiro, analisando o polo fonológico, está ligado ao esquema imagético CONTÊINER. Ao realizar o sinal, a cultura surda brasileira manifesta a conceitualização do corpo humano como um contentor capaz de abrigar "ódio" (abstrato). O segundo aspecto é identificado a partir de uma observação no polo semântico, estruturado em termos de algo (conteúdo) prestes a colapsar naquele recipiente, além de sugerir aquecimento corporal. O terceiro diz respeito à semelhança entre as estruturas fonológica e semântica, as duas sugerem conceitualizações aproximadas: ÓDIO é algo comprimido dentro de um recipiente. Para percebermos essa aproximação dos polos, podemos fazer uma comparação do sinal com a palavra equivalente em língua portuguesa. As estruturas fonológica e semântica da palavra não apresentam nenhuma relação de semelhança ou de aproximação entre si, diferentemente do que ocorre com o sinal e com outras palavras da língua portuguesa, tais como "sussurrar" e "tic-tac".

Outra observação relacionada à conceitualização da estrutura [ÓDIO]/ [ódio], na figura 4, é que estamos diante de uma unidade concernente a uma emoção, portanto, não haveria algo no mundo que pudesse servir de referenciação suficientemente literal para sua estrutura, como acontece com BOLA, ÁRVORE e REVÓLVER, em Libras. Mas como nossa cognição frequentemente recorre a domínios concretos para compreender domínios abstratos, para sinal ÓDIO a cultura surda brasileira realizou uma projeção metafórica com base em suas experiências subjetivas e perceptuais, e encontrou no esquema imagético CONTÊINER e na sensação provocada pelo "ódio" a base para a construção do elo entre as estruturas fonológica e semântica. Nesse caso, as experiências subjetivas e corporais e a percepção de objetos que sugerem compressão, aquecimento e explosão, firmados no esquema imagético CONTÊINER, serviram de base para a relação metafórica e icônica dos polos.

Note que a relação metafórica ocorre a partir dos polos, não apenas no nível do discurso, como na frase "vou explodir de ódio", em Português. Embora estejamos diante de correspondências entre dois domínios, e da metáfora conceitual ÓDIO É UM OBJETO (ou FLUIDO) EM UM CONTENTOR, não há nenhum elo metafórico entre os polos fonológico e semântico da unidade linguística "ódio", diferentemente do que ocorre com o sinal. Mesmo assim, é possível chegar às mesmas conclusões dos estudos realizados por Kövecses (1986), Kövecses (2005) e Lakoff (1987), pioneiros nas investigações das metáforas conceituais ligadas a emoções. Em seus trabalhos, os autores defendem que nossas sensações corporais relacionadas à raiva/ódio fazem-nos associar o corpo como um recipiente pressurizado, o nosso sangue como um líquido em ebulição e a conceitualização de raiva/ódio como o resultado de mapeamentos entre domínios. 
Como acontece em Libras, há frases em Português que sugerem ÓDIO como UM OBJETO (ou FLUIDO) EM UM CONTENTOR: "estou fervendo de tanto ódio" e "o meu ódio só aumenta". Poderíamos pensar que essa mesma metáfora em Português e em Libras ocorre porque as duas línguas estão em contato, e, consequentemente, uma influencia a outra com empréstimos metafóricos. No entanto, essas semelhanças metafóricas não são próprias de línguas em contato. Mesmo culturas geograficamente distantes possuem metáforas correlatas. Essa constatação levou Kövecses $(2005$, p. 38) a levantar três hipóteses: (i) isso ocorre por pura coincidência, (ii) é resultado de empréstimos metafóricos entre as línguas ou (iii) existe alguma motivação universal. $\mathrm{O}$ autor cita o caso das metáforas conceituais "FELIZ É PARA CIMA", "FELICIDADE É LUZ" e "FELICIDADE É UM FLUIDO EM UM CONTÊINER", usadas por três culturas/línguas diferentes e geograficamente distantes uma da outra: chinesa, húngara e inglesa. Aliás, essas metáforas também são encontradas no contexto brasileiro.

Essas semelhanças metafóricas não acontecem somente com culturas ouvintes, as culturas surdas também evidenciam esse fenômeno. Para citar alguns exemplos, trago aqui o sinal DIFICULDADE nas culturas surdas brasileira, francesa, grega e portuguesa. Todas elas compreendem "dificuldade" como um objeto embaralhando o cérebro, algo que está dentro da cabeça fazendo movimentos de entrelaçamento, de zigue-zague, na mente do sinalizante.

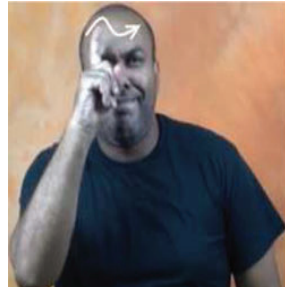

5.a - Em Libras

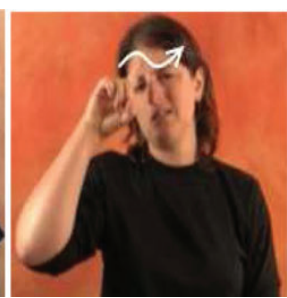

5.b - Em língua de Sinais Francesa

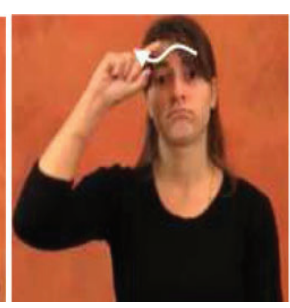

5.c - Em língua de Sinais Grega

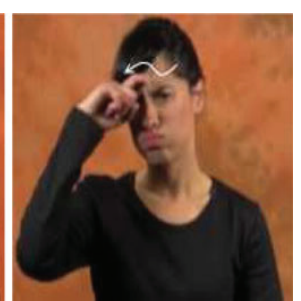

5.d - Em língua Gestual Portuguesa

Figura 5 - Sinal "DIFICULDADE" em quatro línguas de sinais

Fonte: Adaptada de www.spreadthesign.com ${ }^{9}$

Já o sinal ESQUECER é um dos que apresenta maior similaridade em várias línguas de sinais, ${ }^{10}$ e sua conceitualização nos dá a impressão de algo como "retirar/ expulsar alguma coisa da cabeça" nas culturas surdas alemã, americana, austríaca, brasileira, britânica, búlgara, checa, espanhola, estoniana, francesa, indiana, italiana, letã, lituana, portuguesa, romena, russa e ucraniana. Todas elas entendem ESQUECIMENTO como UM OBJETO QUE É RETIRADO/EXPULSO DE UM CONTENTOR. Mas o que leva culturas surdas distantes, diferentes e sem contato a realizarem as mesmas projeções metafóricas em sinais?

\footnotetext{
${ }^{9} \mathrm{Cf}$. em: www.spreadthesign.com

${ }^{10} \mathrm{Cf}$. em: www.spreadthesign.com
} 
Fatos como os que foram ditos acima levam linguistas cognitivos a defenderem princípios de motivação universal por trás das metáforas primárias. E assim como os linguistas cognitivos de línguas oral-auditivas, minha alegação é a de que existe um princípio de motivação universal que pode fazer com que projeções metafóricas nas línguas de sinais sejam parecidas e até mesmo idênticas, principalmente em unidades simbólicas isoladas, onde, a partir de determinadas experiências corporificadas, a cognição realiza correspondências neurais semelhantes, independente da cultura do sujeito e independente do distanciamento geográfico. Mas como a mediação cognitiva está entre a unidade simbólica e o mundo, as culturas surdas também geram metáforas e ícones metaforizados diferentes, ainda que diante de uma mesma experiência corporificada. Por exemplo, diferentemente das culturas surdas citadas acima, ESQUECIMENTO na Língua de Sinais Polonesa parece sugerir algo como APAGAR/ESCURECER LUZ DIANTE DOS OLHOS.

Observando a figura 4 mais uma vez, notaremos que as conceitualizações são as mesmas nas estruturas fonológica e semântica: ambas sugerem ÓDIO como UM OBJETO EM UM CONTENTOR. Porém, ao contrário do que ocorre com os sinais icônicos BOLA e ÁRVORE, a relação de semelhança entre as estruturas fonológica e semântica do item lexical da figura, em tese, não haveria razão para existir, pois sendo abstrata tal emoção não possuiria um objeto concreto no mundo que lhe servisse de referenciação óbvia, literal, não metafórica. Mas as experiências subjetivas e corpóreo-culturais motivaram o surgimento de um tipo específico de iconicidade, a qual passo a chamar de ícone metaforizado, ${ }^{11}$ uma unidade simbólica icônica ligada a um domínio abstrato, com uma projeção metafórica em sua base lexical, unindo imaginação, razão, iconicidade e experiências corpóreo-culturais. As evidências mostram que a cognição realiza correspondências neurais que se refletem nas estruturas do item lexical, proporcionando uma conceitualização baseada em experiências corporificadas e subjetivas, fazendo [ÓDIO]/[ódio] espelhar a iconicidade e refletir a metáfora. Aliás, para a cultura surda brasileira, os fatores externos podem acionar esse objeto enclausurado e proporcionar um movimento mais ou menos violento. Nesse sentido, mesmo diante de algo intangível, a cultura encontrou em um referente concreto todas as características para conceitualizar o abstrato, fazendo surgir o ícone metaforizado.

\footnotetext{
${ }^{11}$ Ainda não encontrei em minhas leituras reflexões sobre esse fenômeno ou hipóteses levantadas sobre esse tipo de iconicidade em línguas de sinais, como faço neste trabalho. De toda forma, é importante destacar que os estudos sobre o signo linguístico, e, consequentemente, sobre a motivação e a iconicidade nas línguas, são vastos e possuem vários pontos de vista. Os mais influentes são os de Saussure (2012), Peirce (2005) e Ullmann (1962). Minha linha de raciocínio consiste em defender, dentre outras coisas, que na LIBRAS existe uma motivação icônica com uma metáfora na base do item lexical, e não apenas quando o item lexical está em uso no discurso, onde é mais comum que haja as correspondências neurais entre os domínios.
} 
Com as hipóteses acima, podemos contrastar o ícone metaforizado com a iconicidade presente em unidades lexicais que não carregam metáforas. Ao comparar ÁRVORE e ÓDIO, a diferença icônica reside no fato de que enquanto no primeiro sinal a iconicidade é justificada pela relação de literalidade dos polos com o objeto no mundo, na segunda a justificação dá-se pelo processo de metaforização em toda a estrutura. Por exemplo, a unidade simbólica ÁRVORE e o objeto no mundo não possuem nenhuma relação metafórica, mas o item lexical manifesta iconicidade. Então, para as correspondências entre [ÁRVORE] e [árvore], há algo físico no mundo oferecendo referência não metafórica (literalidade). Já o sinal ÓDIO e o objeto no mundo possuem uma relação metafórica, onde o vínculo entre [ÓDIO] e [ódio] carrega uma motivação semântica, e o processo que o cria (metaforização icônica) possui um princípio que une razão, imaginação, experiências corpóreo-culturais e iconicidade. Além do mais, enquanto a unidade ÁRVORE está ligada a uma experiência perceptual-concreta, o sinal ÓDIO está ligado a uma experiência perceptual-subjetiva, mostrando que a metaforização icônica também descortina as experiências subjetivas e introspectivas da cultura surda.

Embora exista uma associação com o objeto no mundo na iconicidade, não há uma conexão direta deste com o significado antes da mediação cognitiva. Como para a cultura surda brasileira o ódio propriamente dito promove uma sensação corpórea situada exatamente naquela região, ocupada pelo ponto de articulação do sinal, então existe uma motivaçãa ${ }^{12}$ para que o sinal seja executado aí, e não em outra porção do corpo. Assim, com a motivação do ponto de articulação, com a cognição metaforizando a relação dos polos semântico e fonológico, como ambas as estruturas recebem a mesma conceitualização, então é possível notar que unidades simbólicas com essas características revelam a estrutura da experiência do sujeito, além de evidenciar os processos cognitivos por trás da metáfora, onde o esquema imagético CONTÊINER também serve como base concreta de apoio. A esquematização abaixo resume esse processo que cria ícones metaforizados em línguas de sinais.

${ }^{12}$ Perceba que não estou usando "motivação" como equivalente de "iconicidade". Nesse trabalho, uma unidade simbólica pode muito bem ser motivada sem ser icônica. Por exemplo, o sinal AZUL, em Libras, é motivado pela palavra "azul”, da língua portuguesa, mas não há relações icônicas entre os polos fonológico e semântico, nem da palavra em Português nem do sinal em Libras. Já nos sinais CADEIRA, ÁRVORE e REVÓLVER há motivações icônicas. Também existem outros sinais que parecem não ter motivação alguma: PRECISAR, FAZER, PORQUE, PESSOA entre outros. 


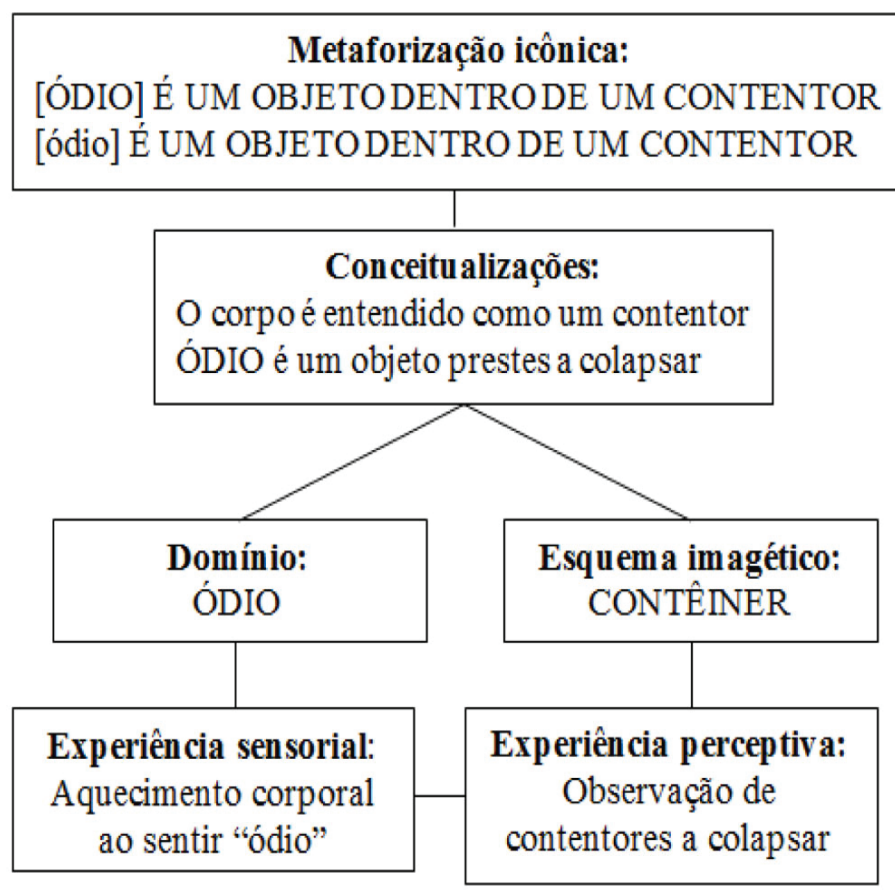

Ilustração 2 - Metaforização icônica

Fonte: Elaborada pelo autor

A minha alegação é a de que isso é parte do processo de metaforização por trás do ícone metaforizado em línguas de sinais, proporcionando que uma mesma experiência gere sinais icônicos semelhantes ou idênticos em culturas surdas relativamente ou radicalmente distantes e diferentes, a exemplo do que mostrei com ESQUECIMENTO nas culturas surdas alemã, americana, austríaca, brasileira, britânica, búlgara, checa, espanhola, estoniana, francesa, indiana, italiana, letã, lituana, portuguesa, romena, russa e ucraniana.

Esse tipo de iconicidade pode ser encontrada em outras unidades simbólicas da Libras: MALDADE é algo assemelhado a um objeto agitando o, ou movimentando-se no, coração. Já AMOR pode ser esvaziado, como mostra a imagem 6, abaixo. Em razão de a cultura surda brasileira situar esses sentimentos no coração, esses sinais são executados exatamente no lado esquerdo do tórax, onde fica o ponto de articulação dessas estruturas simbólicas. 


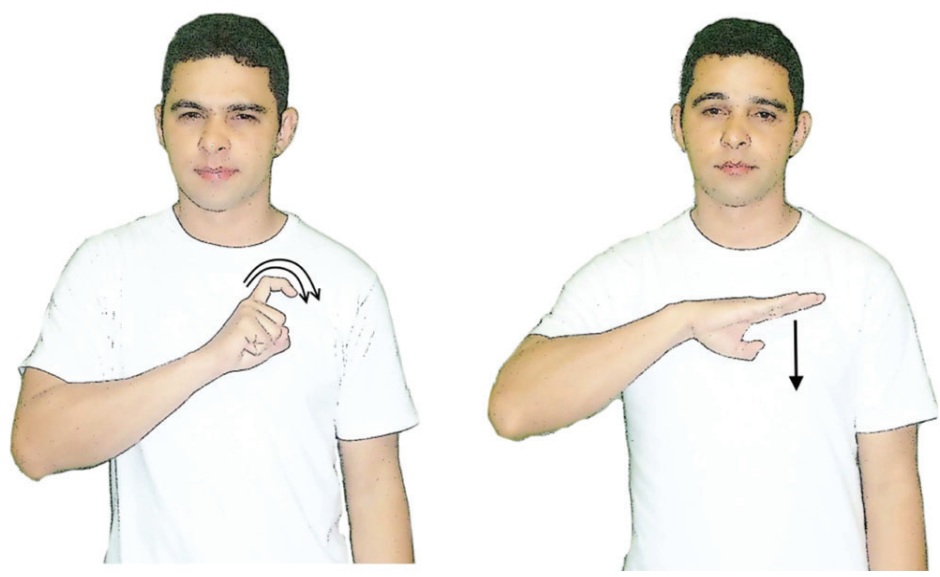

Figura 6 - Exemplos de ícones metaforizados

Fonte: Elaborada pelo autor

Comparando as estruturas [ÓDIO]/[ódio], [MALDADE]/[maldade] e AMOR ESVAZIAR em Libras, vamos perceber que, embora não identifiquemos exatamente os referentes concretos no mundo, podemos concluir que cada uma está baseada no esquema imagético CONTÊINER: o corpo é um contentor. Perceba também que o processo de metaforização icônica nos fornece indícios de que, para a cultura surda brasileira, alguns sentimentos são conceitualizados como objeto, entidade viva, gás ou líquido: ÓDIO pode ser explodido; DIFICULDADE pode rastejar, ziguezaguear pela mente ou embaraçar o cérebro; CARINHO pode ser acariciado; ALÍVIO pode ser diminuído; IDEIAS podem ser conectadas, enviadas, combinadas; AMOR pode ser esvaziado.

Obviamente, chego a essas conclusões a partir de uma perspectiva da Linguística Cognitiva. Contudo, no Estruturalismo vamos encontrar pelo menos três processos de motivação: (i) motivação fonética - as palavras classificadas como onomatopeias são motivadas pelos sons produzidos por seus referentes: toc-toc, pingue-pongue, tic-tac, boom, sussurro; (ii) motivação morfológica derivações e composições são os exemplos, onde os morfemas ou outras palavras unem-se a radicais ou palavras para formar novas unidades lexicais: jardineiro, cantor, planalto, pernalta; (iii) motivação semântica ou metassêmica - processo de analogia entre os sentidos das palavras ou expressões linguísticas: pé-de-cabra, pé-de-moleque, asa da xícara, ele é o cabeça do grupo, ele só tem fogo de palha, estou perdendo meu tempo.

Acima, o último tipo de motivação abrange metáforas no nível lexical e no da expressão, podendo compreender também o ícone metaforizado. Mas mesmo assim, este último possui suas singularidades que o distingue da motivação ocorrida nas palavras relacionadas naquele último grupo. Por exemplo, em "péde-cabra", "pé-de-moleque" e "asa da xícara", por mais que se tenha aí uma conotação metafórica (catacrese é uma forma de metáfora), estamos diante de 
uma motivação semântica que leva em conta dois objetos concretos, e não uma referenciação entre o abstrato e o concreto. Mais do que isso, entre as estruturas fonológica e semântica dessas unidades não há relações icônicas. Já em "ele é o cabeça do grupo", "ele só tem fogo de palha" e "estou perdendo meu tempo", apesar de evidenciarem mapeamentos entre os domínios fonte e alvo, a motivação icônica é inexistente, em virtude de essas expressões não refletirem a relação de iconicidade entre seus polos fonológico e semântico. Em suma, nas motivações citadas em (i), (ii) e (iii), ou existe iconicidade e não metáfora (tic-tac, toc-toc, pingue-pongue etc.) ou metáfora e não iconicidade (pé-de-cabra, asa da xícara, estou perdendo meu tempo etc.).

Por esse prisma, percebo que a iconicidade em língua de sinais segue dois princípios, pelo menos: o princípio da literalidade e o princípio da metaforização. No da literalidade, vamos nos deparar com sinais icônicos que possuem relações literais (não metafóricas) entre seus polos e o referente do mundo: ÁRVORE, CADEIRA, COPO, BOLA, REVÓLVER etc.; no da metaforização icônica, as conceitualizações realizam projeções metafóricas entre os polos da unidade e algum referente, mediado pela cognição, que é identificado como possuindo semelhanças com toda a estrutura simbólica: ÓDIO, DIFICULDADE, CARINHO, MEDO etc. Nessas unidades linguísticas, a cultura surda metaforiza os espaços fonológico e semântico, buscando projetar formas e ações que possuem alguma característica com as sensações (no caso dos sentimentos e emoções) a serem referenciadas. Por isso, unidades que, aparentemente, não deveriam possuir referentes, agora dispõem de um que passou pelo processo de metaforização. Essa perspectiva é importante porque revela como os processos cognitivos fazem associações metafóricas não apenas no discurso ou na frase, mas também em unidades simbólicas isoladas.

\section{CONCLUSÃo}

Como defendido pela Linguística Cognitiva, a relação de nosso corpo com os objetos do mundo e com a cultura na qual estamos inseridos promovem o estabelecimento de estruturas cognitivas diversas, entre elas estão os domínios, os complexos de domínios e os esquemas imagéticos, também fundamentais na conceitualização de unidades simbólicas abstratas. Em Libras, muitas dessas unidades possuem motivação icônica metafórica, como mostrei neste artigo.

Para concluir este trabalho, não a pesquisa, diante do ícone metaforizado, eu tenho três alegações a fazer, por enquanto: (i) a metaforização icônica é o processo que cria o ícone metaforizado em língua de sinais; (ii) o ícone metaforizado evidencia a base imaginativa de nossa razão, mesmo em unidades simbólicas isoladas; e (iii) a relação entre cognição e experiências sensório-motoras da cultura surda promove metáforas tanto nas expressões quanto nos sinais, assegurando também a iconicidade. Portanto, a iconicidade metafórica é um fenômeno claramente analógico, de natureza cognitiva e corpóreo-cultural. 


\section{REFERÊNCIAS}

ClAUSNER, T. C.; CROFT, W. Domains and image schemas. Cognitive linguistcs. v. 10, n. 1, pp. 1-31, 1999.

EVANS, V. A Glossary of Cognitive Linguistics. Salt Lake City: University of Utah Press, 2007.

EVANS, V.; GREEN, M. Cognitive Linguistics: An Introduction. Edinburgh: Edinburgh University, 2006.

FILLMORE, L. W. The second time around: Cognitive and Social Strategies in Second Language Acquisition. Unpublished doctoral dissertation. Stanford University, 1976.

JOHNSON, M. The Body in the Mind: The Bodily Basis of Meaning, Imagination, and Reason. Chicago: University of Chicago Press, 1987.

KÖVECSES, Z. Metaphors of Anger, Pride and Love: A Lexical Approach to the Structure of Concepts. Amsterdam/Philadelphia: John Benjamins Pub. Co., 1986.

KÖVECSES, Z. Metaphor in Culture: universality and variation. New York: Cambridge University Press, 2005.

LAKOFF, G. What is conceptual system? In: OVERTON, W. F.; PALERMO, D. S. The Nature and Ontogenesis of Meaning. Hillsdale, N.J: Lawrence Erlbaum. pp. 41-90, 1994.

LAKOFF, G. Women, Fire, and Dangerous Things: What Categories Reveal About the Mind. Chicago: University of Chicago Press, 1987.

LAKOFF, G.; JOHNSON, M. Metaphors We Live By. Chicago: University of Chicago Press, 2003.

LAKOFF, G; TURNER, M. More Than Cool Reason: A Field Guide to Poetic Metaphor. Chicago: University of Chicago Press, 1989.

LANGACKER, R. W. Foundations of Cognitive Grammar. Vol. 1. Theoretical Prerequisites. Stanford: Stanford University Press, 1987.

LEVINSON, S. C. Relativity in spatial conception and description. In: GUMPERZ, J. J.; LEVINSON, S. C. Rethinking Linguistic Relativity. Cambridge: Cambridge University Press, pp. 177-202, 1996.

PEIRCE, C. S. Semiótica. Tradução J. Teixeira Coelho Netto. São Paulo: Perspectiva, 2005. (Collected Papers).

SAUSSURE, F. Curso de Linguística Geral. Trad. Antônio Chelini, José Paulo Paes e Izidoro Blinkstein. São Paulo: Editora Cultrix, 2012.

SKINNER, B. F. Verbal Behavior. New York: Appleton-Century-Crofts, 1957.

SUTTON-SPENCE, R.; QUADROS, R. M. Poesia em línguas de sinais: traços da identidade surda. In: QUADROS, R. M.(Org). Estudos Surdos I. Perópolis, RJ: Arara Azul, pp. 110-165, 2006.

TALMY, L. How Language Structures Space. Berkeley: Cognitive Science Program, Institute of Cognitive Studies, University of California at Berkeley, 1983.

ULLMANN, S. Semantics: An Introduction to the Science of Meaning. New York: Barnes \& Noble, 1962.

WILCOX, S. Cognitive iconicity: Conceptual spaces, meaning, and gesture in signed languages. In: Cognitive Linguistics, v. 15, n. 2, pp. 119-147, 2004. 